\title{
PEMANFAATAN DRONE UNTUK PEMETAAN POTENSI EKOWISATA DI KECAMATAN PANCA JAYA, MESUJI
}

\author{
Mochamad Firman Ghazali ${ }^{1}$, Hesti ${ }^{2}$, I Gede Boy Darmawan²*, \\ ${ }^{1}$ Jurusan Teknik Geodesi Universitas Lampung, Bandar Lampung \\ ${ }^{2} J u r u s a n$ Teknik Geofisika Universitas Lampung, Bandar Lampung \\ Jl. Prof. Sumantri Brojonegoro No.1 Bandar Lampung 35145 \\ Penulis Korespodensi : igedeboy@staff.unila.ac.id
}

\begin{abstract}
Abstrak
Perlunya kegiatan pemetaan potensi ekowisata di Kecamatan Panca Jaya berkaitan dengan upaya pemberdayaan masyarakat desa. Kecamatan ini merupakan wilayah berupa dataran rendah dengan mayoritas penduduknya bekerja di bidang pertanian dan perkebunan. Penurunan harga komoditas perkebunan menyebabkan banyak petani mengalihfungsikan lahan perkebunan menjadi tanaman singkong. Namun secara geologi, wilayah ini didominasi oleh batuan endapan rawa yang memiliki potensi kandungan batubara muda. Kurangnya data potensi lokasi wisata di daerah ini menyebabkan sedikitnya perhatian masyarakat terhadap potensi ekowisata di wilayah mereka. Pengabdian ini bertujuan untuk mengatasi permasalahan tersebut dengan memetakan potensi ekowisata baru yang dapat dikembangkan dan dikelola oleh masyarakat, mengedukasi masyarakat dalam peningkatan kualitas dan keunggulan/ kearifan lokal yang berimbas pada peningkatan nilai ekonomi kawasan ekowisata dengan pemanfaatan teknologi informasi seperti drone. Manfaat dari pengabdian ini adalah terpetakannya potensi ekowisata yang dapat dikembangkan dan dikelola oleh masyarakat serta terbentuknya media promosi video profil kawasan wisata yang dapat disebarkan melalui media internet sehingga wisatawan dapat dengan mudah mengenal dan tertarik untuk berkunjung ke Panca Jaya.
\end{abstract}

Kata kunci: Drone, Ekowisata, Mesuji, Panca Jaya, Pemetaan

\section{Pendahuluan}

Kecamatan Panca Jaya merupakan bagian dari wilayah Kabupaten Mesuji dengan luas wilayah sekitar 9.868 Hektar. Secara administratif Kecamatan Panca Jaya terbagi menjadi 7 desa yaitu Mukti Karya, Adi Luhur, Fajar Baru, Adi Mulya, Fajar Asri, Fajar Indah, Adi Karya Mulya. Sejak dimekarkan menjadi Kecamatan definitif, wilayah administrasi Kecamatan Panca Jaya yang terdiri dari 7 Desa/ Kelurahan dimana di Tahun 2015 memiliki 41 Rukun Kampung/Desa (RK), 118 Rukun Tetangga (RT). Selain dengan Rukun Kampung (RK) dan Rukun Tetangga (RT), Kecamatan Panca Jaya pun dilengkapi oleh adanya pembentukan Badan Perwakilan Desa (BPD) serta Pertahanan Sipil (Hansip). Di Tahun 2015 jumlah Badan Perwakilan Desa (BPD) yang dimiliki di Kecamatan Panca Jaya sebanyak 41 Anggota dan Jumlah anggota Hansip yang dimiliki pun sebanyak 41 anggota (BPS, 2016).

Kecamatan Panca Jaya merupakan salah satu kecamatan di Kabupaten Mesuji dengan mayoritas penduduknya mengusahakan bidang pertanian sebagai sektor utama mata pencaharian masyarakat. Dilihat dari subsektor pendukungnya, kontribusi subsektor tanaman bahan makanan (tabama) dan subsektor perkebunan merupakan yang terbesar. Kurang lebih dua tahun terkhir harga komoditi perkebunan seperti karet dan sawit mengalami enururan harga yang cukup signifikan, sehingga tidak sedikit petani yang mengalihfungsikan lahan perkebunannya menjadi tanaman ubi kayu (BPS, 2016).

Pemanfaatan teknologi informasi masih kurang dapat dimaksimalkan untuk membantu membangun profil dan promosi ekowisata di Panca Jaya oleh masyarakat setempat. Kondisi ini dapat kita lihat dari sedikitnya informasi detil terkait peta kawasan wisata, informasi pengelola objek wisata dan keunggulan/kearifan lokal objek wisata. Perlunya pendampingan dalam penggunaan teknologi informasi untuk membuat video profil kawasan wisata yang memanfaatkan drone juga dapat menjadi salah satu aspek yang dapat dilakukan 
melalui kegiatan pengabdian kepada masyarakat (Zaenudin dkk., 2019).

Oleh karena itu, kegiatan ini diharapkan mampu membantu masyarakat Panca Jaya untuk memetakan dan mengoptimalisasikan potensipotensi ekowisata yang ada di kawasan ini. Selain itu, kegiatan ini menjadi langkah awal peran serta tim dalam upaya mengedukasi masyarakat setempat dari aspek pengetahuan bentang alam, geologi, flora dan fauna, aspek pendidikan dan aspek ekonomi (bisnis ekowisata), untuk meningkatkan upaya masyarakat setempat dalam peningkatan kualitas promosi maupun pengelolaan ekowisata.

\section{A. Konsep Ekowisata}

Ekowisata (Ecotourism) adalah kosakata yang cukup dikenal dalam kepariwisataan nasional. Istilah itu lebih populer dibanding geowisata (ecotourism), atau agrowisata misalnya. Namun demikian, di dalam UU No. 9/1990 tentang kepariwisataan, selain wisata agro, baik ekowisata maupun geowisata memang tidak disebut-sebut (Brahmantyo \& Bachtiar, 2009; Rusita dkk., 2016; Walimbo dkk., 2017). Jika di Amerika Serikat, geowisata identik dengan ekowisata, di belahan benua lain, geowisata ditempatkan sebagian bagian dari wisata alam minat khusus yang prinsipprinsipnya mengikuti kaidah-kaidah ekowisata. Ekowisata bagaimana pun harus tunduk pada prinsip-prinsip berwisata yang berwawasan lingkungan dan berkelanjutan sesuai Kesepakatan Quebec 2002 (Fandeli \& Mukhlison, 2000; Fandeli, 2002; Brahmantyo dkk, 2017).

\section{B. Rumusan Permasalahan}

Ada tiga permasalahan yang ingin di jawab dengan kegiatan ini yaitu bagaimana memetakan potensi baru ekowisata di Panca Jaya untuk mendukung peningkatan nilai keekonomisan kawasan. Bagaimana mengoptimalisasi peran serta masyarakat dalam peningkatan kualitas dan keunggulan/kearifan lokal yang berimbas pada peningkatan nilai ekonomi di Panca Jaya dan bagaimana membantu masyarakat dalam peningkatan pemanfaatan teknologi informasi untuk media promosi profil kawasan wisata di Panca Jaya. Kegiatan ini juga bertujuan untuk memberikan edukasi masyarakat tentang optimalisasi peran serta masyarakat dalam peningkatan kualitas dan keunggulan/kearifan lokal yang berimbas pada peningkatan nilai ekonomi kawasan Panca Jaya. Selain itu, kegiatan ini diharapkan dapat membantu masyarakat dalam peningkatan pemanfaatan teknologi informasi untuk media promosi (dengan Drone) profil kawasan wisata Panca Jaya.

\section{Manfaat Kegiatan}

Kegiatan ini diharapkan dapat memberikan manfaat kepada masyarakat di Panca Jaya seperti terpetakannya potensi ekowisata yang dapat dikembangkan dan dikelola oleh masyarakat di Panca Jaya, sehingga memperkaya keragaman objek yang dapat dinikmati oleh wisatawan. Dengan kegiatan ini juga diharapkan teredukasinya masyarakat tentang peran serta mereka dalam peningkatan kualitas dan keunggulan/kearifan lokal sehingga berimbas pada peningkatan nilai ekonomi kawasan. Manfaat lainnya adalah dengan memanfaatkan Drone untuk terbentuknya media promosi (dengan Drone) berupa video profil kawasan wisata yang dapat disebarkan melalui media internet sehingga wisatawan dapat dengan mudah mengenal dan tertarik untuk berkunjung ke Panca Jaya.

\section{Bahan dan Metode}

Untuk pemetaan dan pengambilan video dari atas permukaan telah dikembangakan teknologi baru baik dalam eksplorasi sumber daya alam maupun ekowisata yaitu dengan menggunakan bantuan teknologi "UAV" (Unmanned Aerial Vehicle) atau Drone. UAV dapat digunakan sebagai alternatif solusi untuk pemetaan udara.

\section{A. Bahan/Peralatan Drone}

Drone (UAV) atau disebut wahana udara tak berawak (Gambar 1) merupakan sebuah wahana

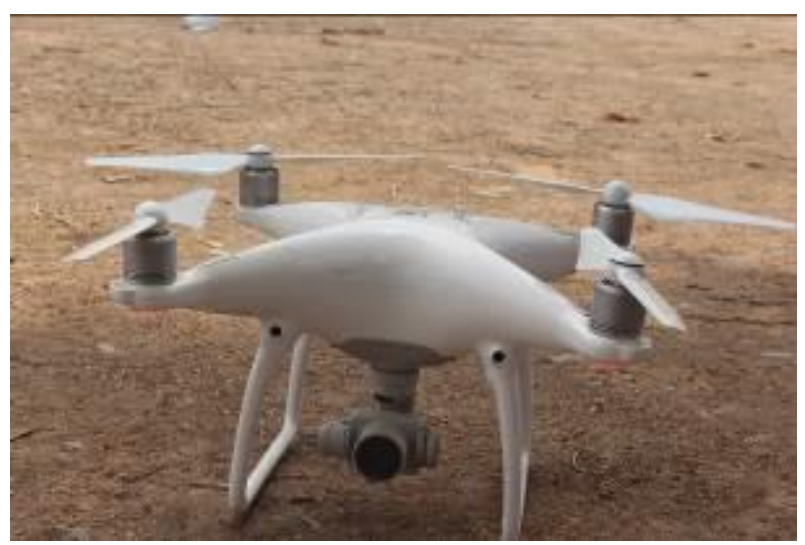

Gambar 1. Persiapan penggunaan drone Phantom 4 untuk mengambil gambar dan video dari udara. terbang yang mempunyai kemampuan dapat beroperasi tanpa adanya pilot yang mengendalikan pesawat tersebut (Lovita dkk., 2017; Hartono \& Darmawan, 2019; Rahmad, 2019). UAV telah berkembang pesat seiring dengan kemajuan di 
bidang teknologi elektronika dan komunikasi. UAV telah dapat digunakan untuk membantu mamantau pengawasan kebakaran hutan, foto udara, pencarian korban bencana dan lain-lain. UAV dapat dikendalikan secara manual maupun secara otomatis.

Pada kegiatan ini, Drone yang digunakan adalah Drone Phantom 4 dari DJI. Drone ini memiliki empat baling-baling dan dilengkapi dengan kamera. Kamera dengan resolusi 20 MPx mampu melakukan pengambilan video dan pemotretan udara dengan cukup baik. Kamera ini juga telah dilengkapi dengan gimbal yang mampu menstabilkan getaran dan guncangan saat pengambilan gambar sambil terbang.

\section{B. Metode dan Tahapan Kegiatan}

Kegiatan yang akan dilaksanakan meliputi studi pustaka tentang pengembangan ekowisata, melakukan visualisasi bentang alam, kualitas air permukaan, foto dan video pada obyek wisata. Terakhir mendeskripsikan obyek wisata, diskusi (FGD) dan pembuatan promosi wisata.

Prosedur kerja yang akan diterapkan dalam kegiatan ini untuk mendukung penerapan IPTEKS/metode yang ditawarkan meliputi pemetakan kondisi alam dengan menerbangkan Drone Phantom 4 untuk mengakuisisi foto dan video dikombinasikan dengan pemetaan potensi melalui pengamatan langsung di lapangan dengan melibatkan mitra. Pembuatan video profil wisata untuk media promosi yang dapat dipublikasikan melalui internet serta membantu publikasikan hasil tersebut. Selain itu pengukuran kualitas air permukaan juga dilakukan dalam mendukung data kondisi awal air permukaan yang berdampak langsung terhadap tanaman unggulan dalam kawasan ekowisata di Panca Jaya.

\section{Hasil dan Pembahasan}

Hasil-hasil yang sudah dicapai dari kegiatan ini meliputi pertemuan diskusi dan komunikasi dengan masyarakat dan kecamatan. Diskusi bersama beberapa pengurus desa serta peninjauan lokasi potensi ekowisata di kawasan Panca Jaya (Gambar 2).
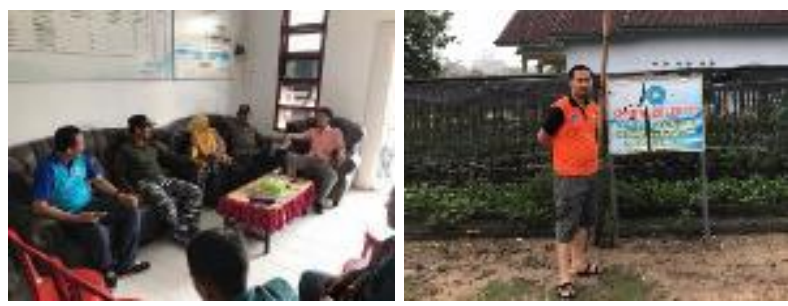

Vol 4 No 1 Maret 2020
Gambar 2. Kegiatan diskusi dan peninjauan lokasi potensi kebun ekowisata di Panca Jaya.

Dalam kegiatan peninjauan juga dilakukan pengambilan sampel dan pengukuran kualitas air tanah (Gambar 3). Kegiatan ini menghasilkan sebaran nilai $\mathrm{pH}$ air, TDS dan EC dari sumur warga di sekitar lokasi seperti yang disajikan pada Tabel 1 berikut ini.

Tabel 1. Hasil pengukuran kualitas air di beberapa lokasi sumur dekat tanaman potensi ekowisata.

\begin{tabular}{|c|c|c|c|c|}
\hline No & Lintang Bujur & $\mathbf{p H}$ & $\begin{array}{c}\text { TDS } \\
(\mathbf{p p m})\end{array}$ & $\begin{array}{c}\text { EC } \\
(\mu \mathrm{s} / \mathrm{cm})\end{array}$ \\
\hline 1 & $-3,91887105,258$ & 7,10 & 363 & 726 \\
\hline 2 & $-3,89036105,284$ & 5,96 & 28 & 56 \\
\hline 3 & $-3,91781105,284$ & 7,70 & 367 & 734 \\
\hline 4 & $-3,96273105,290$ & 5,83 & 106 & 212 \\
\hline 5 & $-3,95754105,261$ & 7,89 & 161 & 322 \\
\hline 6 & $-3,98192105,287$ & 6,24 & 92 & 182 \\
\hline 7 & $-4,00709105,288$ & 6,76 & 76 & 152 \\
\hline
\end{tabular}
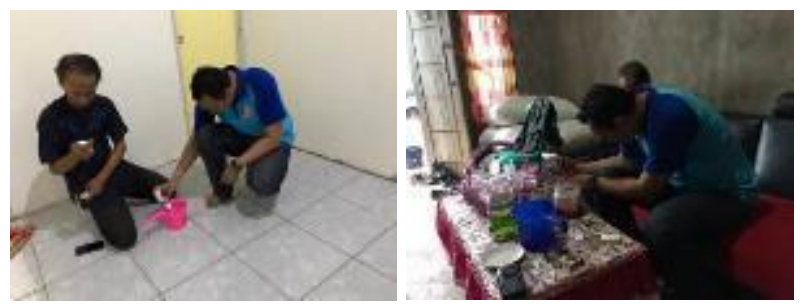

Gambar 3. Kegiatan pengambilan sampel air dan pengujian kualitas air danau di laboratorium.

Hasil peninjauan dilanjutkan dengan kegiatan pemetaan dan pengambilan video dengan menggunakan drone untuk identifikasi daerah potensi ekowisata di Panca Jaya. Kegiatan ini meliputi Persiapan dan setup drone untuk pengambilan gambar dan video serta pemilihan jalur terbang dan lokasi objek gambar maupun video. Beberapa hasil pemetaan dengan menggunakan drone di lokasi kegiatan ditunjukkan oleh Gambar 4. Lokasi pengambilan data difokuskan pada kawasan yang berpotensi untuk dikembangkan sebagai area 


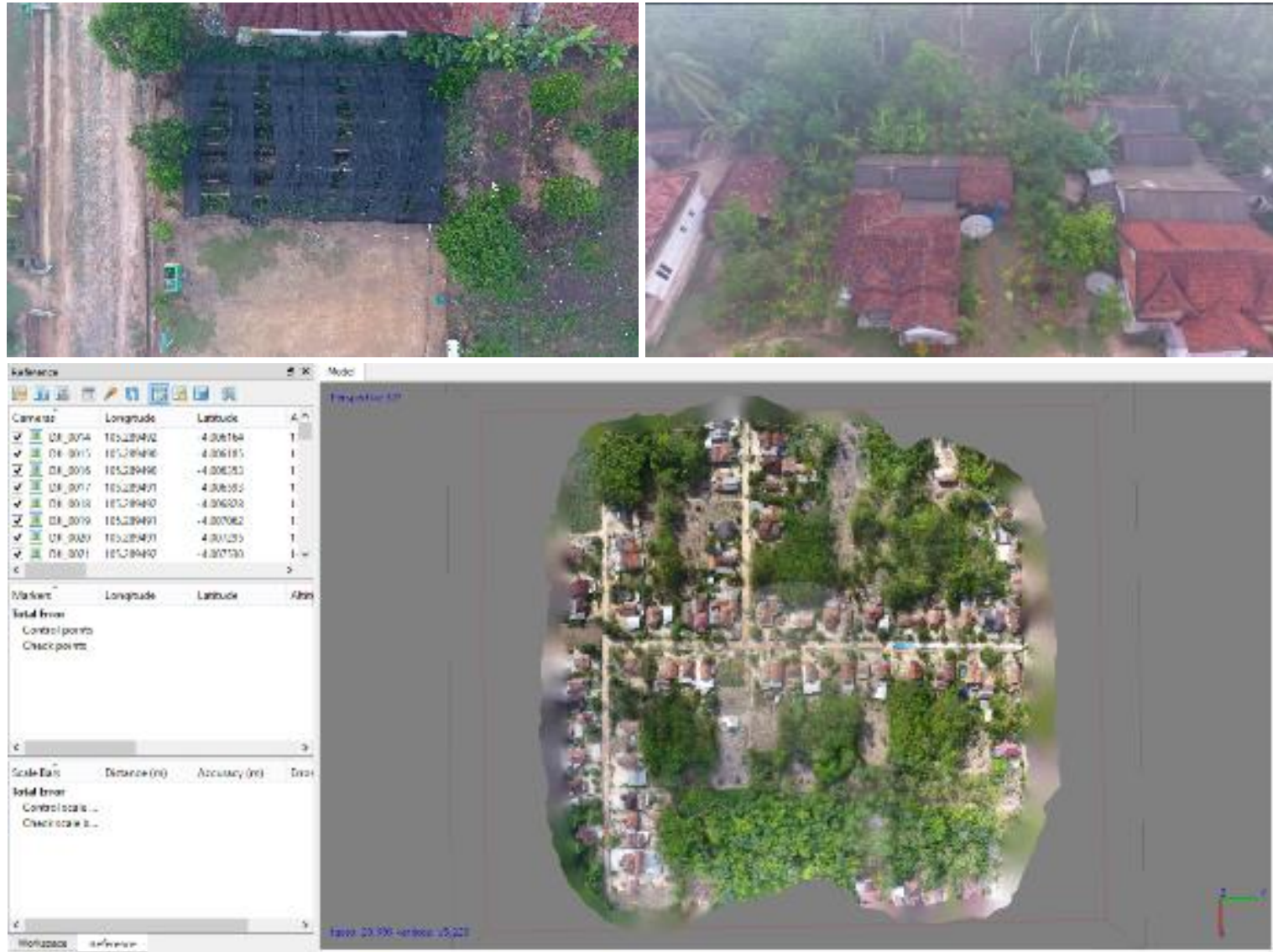

Gambar 4. Beberapa hasil pemotretan udara di area potensi kawasan ekowisata di Panca Jaya, Mesuji.

wisata yang mendukung pengembangan kawasan ekowisata di Panca Jaya, Mesuji.

Seluruh kegiatan tersebut telah berhasil dilakukan dengan baik dan menghasilkan beberapa lokasi potensial untuk pengembangan ekowisata di Panca Jaya, Mesuji. Beberapa potensi tersebut antara lain kawasan agrowisata belimbing, jeruk, sayuran pekarangan dan buah naga serta kawasan olahraga motorcross. Kawasan agrowisata belimbing terpusat di Desa Fajar Asri yang telah berhasil membudidayakan beberapa kebun belimbing. Namun pemanfaatan yang selama ini dilakukan oleh warga hanya sebatas sebagai buah konsumsi. Kegiatan ini berhasil mengidentifikasi potensi pengembangan kawasan ini, salah satunya sebagai sentra produk olahan belimbing seperti selai dan sirup belimbing.

Untuk kawasan yang dapat dikembangkan sebagai agrowisata jeruk teridentifikasi di Desa Adi Mulyo. Daerah ini memiliki kebun jeruk yang saat ini belum berproduksi (berbuah) sehingga penataan kawasan masih tahap awal. Hasil observasi awal menunjukkan kondisi tanaman yang cukup baik dan sehat. Hal ini mengindikasikan area perkebunan jeruk dapat tumbuh dengan baik dan didukung oleh kondisi alam.

Hasil identifikasi lainnya menunjukkan potensi tanaman sayuran pekarangan seperti sawi, kangkung serta terong maupun buah naga telah dimulai di Desa Fajar Baru dan Adi Luhur. Kedua desa ini berpotensi untuk mengembangkan kawasan ekowisata berbasis agrowisata untuk tanaman tersebut. Salah satu contoh metode budidaya tanaman sayuran pekarangan yang ada di Desa Adi Luhur adalah dengan menggunakan waring sebagai pagar tanaman agar tidak mudah diganggu oleh hewan peliharaan seperti ayam dan bebek. Bahkan untuk tanaman buah naga sudah banyak di tanam di pekarangan rumah warga.

Salah satu potensi wisata yang menarik di Panca Jaya adalah adanya lintasan motorcross tipe grass track di Desa Mukti Karya. Sirkuit ini telah beberapa kali digunakan untuk event lomba yang salah satunya disponsori oleh BMX. Pengembangan kawasan ini bisa menjadi salah satu pelengkap kawasan ekowisata di Panca Jaya Mesuji. Beberapa foto area potensi ekowisata tersebut ditunjukkan oleh Gambar 5 berikut ini. 

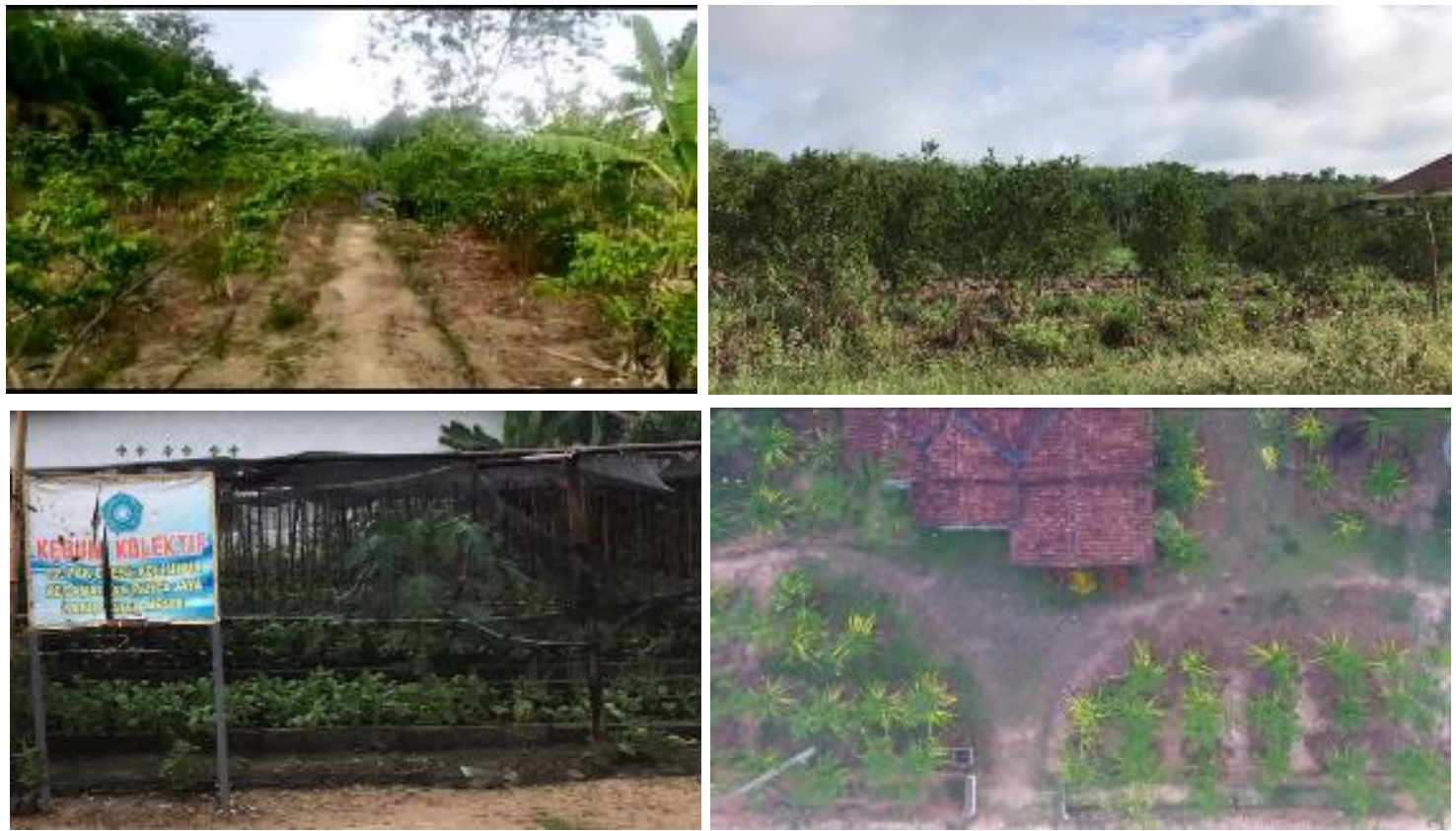

Gambar 5. Lokasi potensi pengembangan kawasan ekowisata berbasis agrowisata meliputi tanaman belimbing, jeruk, sayuran pekarangan dan buah naga di Panca Jaya, Mesuji.

\section{Kesimpulan}

Kegiatan pemetaan dan identifikasi lokasi ekowisata dengan drone dapat mengoptimalisasi potensi wisata di Panca Jaya. Beberapa lokasi ekowisata yang berhasil dipetakan berada di 5 dari 7 desa dengan obyek tanaman agrowisata seperti belimbing, jeruk, buah naga dan sayuran pekarangan serta sirkuit grass track. Pengembangan ekowisata Panca Jaya akan sangat baik jika elemen masyarakat, aparatur desa dan kecamatan maupun bappeda Mesuji dapat bersinergi dalam pengembangan selanjutnya.

Pelajaran terpenting dalam kegiatan ini adalah bahwa potensi ekowisata di Panca Jaya yang ada sudah dipahami dengan baik oleh kelompok masyarakat setempat, tetapi perlu pendampingan agar potensi tersebut dapat berdayaguna dan bermanfaat lebih bagi masyarakat setempat. Pengolahan produk agrowisata sampai dengan pengemasan dan pemasaran bahkan promosi merupakan sebuah keharusan, dan sinergi pemerintahan, masyarakat dan kelompok relawan perlu didayagunakan secara maksimal.

Untuk perbaikan selanjutnya, seluruh elemen harus diajak dan dimotivasi tentang kegiatan pemberdayaan ekowisata dengan penerapan teknologi terbaru (IPTEK secara sederhana) untuk pemetaan bentang alam, sumber daya air, lingkungan, budaya dan teknologi, serta pengelolaan potensi desa wisata khususnya agro dan mempromosikannya ke masyarakat luas. Sehingga potensi alam di lokasi mereka dapat didayagunakan dan memberikan manfaat bagi masyarakat setempat.

\section{Ucapan Terima Kasih}

Terima kasih disampaikan kepada LPPM UNILA dan Fakultas Teknik yang telah mendanai kegiatan ini. Ucapan terima kasih juga kami ucapkan kepada Bapak Camat Panca Jaya beserta seluruh Kepala Desa di Kecamatan Panca Jaya Mesuji yang telah banyak membantu dalam kegiatan ini.

\section{Daftar Pustaka}

Badan Pusat Statistik. (2016). Statistik Daerah Kecamatan Panca Jaya. Katalog BPS: 1100002.1811030, Badan Pusat Statistik Kabupaten Mesuji.

Brahmantyo, B dan Bachtiar, T. (2009). Wisata Bumi Cekungan Bandung. Truedee Pustaka, Bandung.

Brahmantyo H., Baiquni M., Fandeli C., \& Widodo T. (2017). Persepsi masyarakat setempat dan pegawai pemerintah daerah terhadap dampak pembangunan pariwisata : studi kasus di kawasan Kota Tua. Jurnal Khasanah Ilmu, 8(1), 10-19.

Fandeli, C. \& Mukhlison. (2000). Pengusahaan Ekowisata. Fakultas Kehutanan Universitas Gadjah Mada, Bulaksumur, Yogyakarta.

Fandeli, C. (2002). Perencanaan Kepariwisataan Alam. Fakultas Kehutanan Universitas Gadjah Mada, Bulaksumur, Yogyakarta.

Hartono, D., \& Darmawan, S. (2019). Pemanfaatan Unmanned Aerial Vehicle (UAV) Jenis Quadcopter untuk Percepatan Pemetaan Bidang 
Tanah (Studi Kasus: Desa Solokan Jeruk Kabupaten Bandung). REKA GEOMATIKA, (1), 30-40.

Lovita, M., Yosritzal, \& Purnawan. (2017). Pemanfaatan Drone Pada Penelitian Keselamatan Lalu Lintas di Persimpangan. Prosiding 4th ACE National Conference Universitas Andalas (pp. 527-532).

Rahmad, R. (2019). Pemanfaatan Drone DJI Phantom 4 Untuk Identifikasi Batas Administrasi Wilayah. JURNAL GEOGRAFI, 11(2), 218-223.

Rusita, Walimbo, R., Sari, Y. \& Yanti, M. (2016). Studi Potensi Obyek dan Daya Tarik Wisata Alam Air
Terjun Wiyono di Taman Hutan Raya Wan Abdul Rahman, Provinsi Lampung. INFO TEKNIK, 2(17), 165-186.

Walimbo, R., Wulandari, C. \& Rusita. (2017). Studi Daya Dukung Ekowisata Air Terjun Wiyono di Taman Hutan Raya Wan Abdul Rahman Provinsi Lampung. Jurnal Sylva Lestari, 1(5), 47-60.

Zaenudin, A., Suharno, Haerudin, N., Darmawan, I. G. B. (2019). Pemetaan Potensi Geowisata dan Upaya Peningkatan Partisipasi Masyarakat Dalam Tata Kelola Pariwisata di Air Naningan, Tanggamus. SENAPATI, 1(1), 46-51. 